brought to my attention during several months of work as assayer at the Tintic Smelter.

During that time we had considerable trouble in checking with the mine assayer in our assays for silver.

The ores on which varying results were obtained were oxidized lead ores, containing from forty to sixty per cent. of silica, about five per cent. of iron and two per cent. of lime, from fifteen to forty per cent. of lead, from twenty to eighty ounces of silver, never more than two per cent. of zinc, about one per cent. of sulphur, and only a trace of copper.

The regular (stock) flux used on these ores was made up as follows:

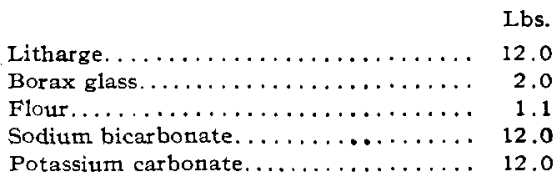

About eighty grams of the above flux were charged with a half-assay ton of ore. The assay was made by fusion in a twenty-gram crucible, using a cover of powdered borax glass. A lead button weighing from twenty-one to twenty-four grams was thus obtained.

To minimize volatilization losses these buttons were cupelled, as far as possible, separately from buttons obtained from fusions of ores containing copper and zinc, on account of the fact that the former required a lower temperature of cupellation, particularly at the blicking point.

Three, and sometimes four, rows of cupels were charged at one time, an extra row of empty cupels being placed in front to prevent rapid temperature changes. Empty crucibles were used in the back of the muffle to regulate the heat.

The silver values which we obtained were almost invariably higher than those obtained by the mine assayer and, in case of dispute, very commonly higher than those of the umpire. This variation sometimes amounted to as much as an ounce, the splitting limit for settlement being five-tenths of an ounce.

The lower results obtained by the second and third parties I attribute to two causes:

(1) Higher temperature of cupellation.

(2) Excessive amounts of litharge in the fluxes.

With regard to temperature of cupellation, I understand that it is rather common practice in some assay offices, in running control and umpire work, to cupel in single rows. In so doing the cupels of ten show much heavier "feathers" on one side than on the other-evidence that the temperature was higher than necessary.

Moreover, if buttons of the character described be cupelled with buttons containing copper, the latter will require a higher cupelling temperature, involving a correspondingly greater volatilization loss in the former.
With regard to excessive use of litharge, I made up two other fluxes, similar to our own stock flux, but containing, in the first case (A) about fifty grams of litharge, and in the second case (B) seventy-five grams of litharge per half-assay ton charge.

Three ores were assayed using these different fluxes, care being taken to cupel buttons from different fluxes in the same muffle, so that the temperature of cupellation should be as nearly as possible the same in each case.

The average of results obtained were as follows:

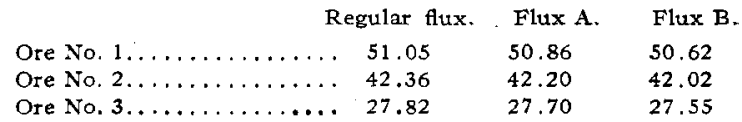

The figures given are ounces of silver per ton of ore.

The use of litharge in excess of the amount necessary to bring down a lead button of proper size on such ores as the above is, of course, unnecessary, but such practice I find is not uncommon, especially where a regular stock flux is used, containing an excess of litharge, the function of which is, as a "cleanser," to throw any copper or other impurities into the slag.

UNIVERSITY OF UTAH.

\section{RAPID ESTIMATION OF AVAILABLE CALCIUM OXIDE IN LIME USED IN CYANIDE WORK.}

\author{
By L. W. BAHNeY. \\ Received August 2, 1910.
}

Lime is the alkali that is almost universally added to the solutions in the cyanide process of gold and silver extraction for maintaining the so-called protective alkalinity.

The value of lime for this purpose depends upon the percentage of calcium oxid which it contains, and three factors determine this.

First, purity of the limestone.

Second, degree of burning temperature and time.

Third, length of time it may have been stored and whether it has been damp or dry during this period of storage.

These three factors combine to make the quality of lime which is bought in the open market rather uncertain.

While lime bought in the United States from a reliable firm, which thoroughly burns a pure limestone and delivers at once to the consumer from the kilns, may be of a fairly high and uniform composition, yet in Mexico and Central America, where it is purchased from many small producers who of ten have a poor grade of limestone to start with, and whose kilns are small and crude and who use as little fuel as possible, the quality of the lime is quite variable.

The determination of calcium by the gravimetric method, with the necessity of also determining the proportion of carbon dioxide, silica and iron, requires 
too much time, and is usually out of the question for the isolated plant without the necessary apparatus and the services of a skilled chemist.

The calculating of all the calcium found to calcium oxid, although sometimes done, is manifestly very inaccurate.

Several methods ${ }^{1}$ of titrating by means of a standard acid have been described and no doubt give good results, which are sufficiently accurate for a technical method, and the objections to these are that they involve the preparation of a standard solution of some acid, usually $\mathrm{N} /$ Io $\mathrm{HCl}$, which cannot be weighed out but must be standardized with some other standard solution. The idea suggested itself of using the solution which is employed in determining the alkalinity of the cyanide solutions.

Solutions of the following acids have been used by diferent operators for this purpose: sulphuric, nitric, hydrochloric and oxalic. Oxalic acid is perhaps the best for this purpose because a standard solution can be prepared by weighing the solid acid and dissolving it in water.

While this method of standardization is open to the objection that the hydration of the acid may vary somewhat, yet it yields a solution sufficiently accurate for technical work, and so far as I am aware, the use of oxalic acid for this purpose has not been suggested.

Pure calcium oxid was prepared by selecting pure white crystals of calcite, grinding fine in an agate mortar and igniting in a platinum crucible over a strong blast until constant weight resulted.

This oxid was cooled in a desiccator, then ground in an agate mortar to pass 200 mesh, and the calcium oxid determined gravimetrically; the result was 99.98 per cent. against a theoretical roo per cent.

This calcium oxid was then used as a standard throughout the succeeding tests.

Similar weighed portions were titrated with decinormal $\mathrm{HCl}$ and oxalic acid, using phenolphthalein as indicator, and where $44,2 \mathrm{cc}$. of $\mathrm{HCl}$ were required, $44.6 \mathrm{cc}$. oxalic acid completed the reaction. The solution of the oxalic acid used in the subsequent experiments was made by dissolving 14.6068 grams in enough distilled water to make a liter. The first experiments were made upon small amounts of 140 mg., to which was added Ioo cc. of water before titration, the idea being to have just enough lime present to be theoretically soluble in that amount of water.

As this is a rather small amount to handle and the method given in Treadwell and $\mathrm{Hall}^{2}$ of weighing out I4. OOO grams, making IOOO cc. of emulsion, removng Ioo cc., again diluting to iooo cc., and removing Ioo cc. for titration, did not give results which

1 Sutton's "Volumetric Analysis." "Quantitative Analysis." Vol. II. Treadwell and Hall. Trans. Met. Soc. S. Africa.

2 Vol. II, p. 453 , checked upon low-grade limes and is open to the objection of extra manipulation, larger amounts were tried and were introduced directly into the flask in which the determination was to be carried out.

The weight of lime to be taken was calculated so that each cubic centimeter of oxalic acid solution should represent I per cent. of calcium oxid:

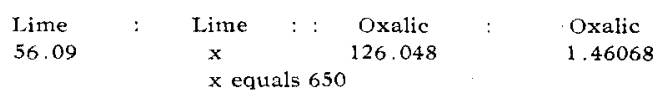

This weight in milligrams (650) was then used in all the tests, and the following table will show results which are satisfactory for a technical method.

The titrations were made in the cold by introducing $650 \mathrm{mig}$. of the sample into a $300 \mathrm{cc}$. Erlenmeyer flask containing $50 \mathrm{cc}$. of distilled water, using phenolphthalein as indicator.

$\begin{array}{ccc}\text { Calcium carbonate. } & \text { Calcium oxide. } \\ \text { Per cent. present. } & \text { Calcium oxide. } & \text { Per cent. found. } \\ 95 & 5 & 5.2 \\ 90 & 10 & 10.3 \\ 85 & 15 & 15.3 \\ 80 & 20 & 20.5 \\ 75 & 25 & 25.0 \\ 70 & 30 & 30.2 \\ 65 & 35 & 35.0 \\ 60 & 40 & 40.0 \\ 55 & 45 & 45.0 \\ 50 & 50 & 49.8 \\ 45 & 55 & 54.5 \\ 40 & 60 & 59.9 \\ 35 & 65 & 64.8 \\ 30 & 70 & 69.6 \\ 25 & 75 & 74.5 \\ 20 & 80 & 79.2 \\ 15 & 85 & 84.8 \\ 10 & 90 & 90.0 \\ 5 & 95 & 94.7 \\ 0 & 100 & 100.0\end{array}$

This series indicates that calcium oxid, in the presence of calcium carbonate, can be determined by this method within a fair degree of accuracy.

Silica, which is present in most limes, does not interfere.

Magnesia, which is also. present in most limes, in greater or lesser amount, is very slightly soluble in water and shows a faint reaction with the indicator, but it is of no value as an alkali in cyanide work and should not be shown in a determination of the available alkali in lime to be used for this purpose.

Fortunately the point where the alkalinity due to $\mathrm{CaO}$ stops is readily recognized after a little practice, for the color is a vivid pink while that of $\mathrm{MgO}$ is faint, and the color in the titration of $\mathrm{MgO}$ disappears with the addition of only one- or two-tenths of a cubic centimeter of the oxalic acid solution, and the color returns very slowly and feebly while that of lime is rapid and sharp.

This is illustrated by the fact, that a titration of pure $\mathrm{CaO}$ required only 5 minutes while the same amount of $\mathrm{MgO}$ required three and one-half hours.

In order to test the method in the presence of magnesia, two samples of limestone containing magnesia were ground to 200 mesh and titrated (after ignition 
in platinum crucibles to constant weight). The $\mathrm{CaO}$ was determined by the gravimetric method in each sample, there was no silica present and no more than a trace of iron, with these results:

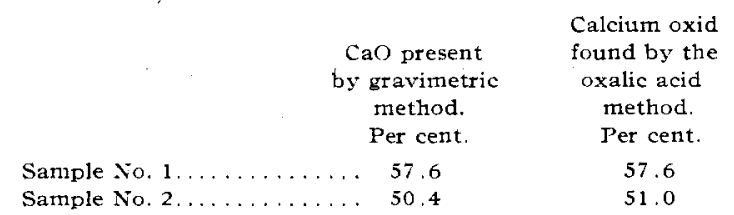

This indicates that the magnesia does not interfere. Its presence and approximate amount can be judged by the behavior of the titration and quite accurately by continuing the titration if one can spare the time needed.

Iron oxid is sometimes present in impure limes in considerable amount and it obscures or masks the color of the indicator, but if the precipitate be allowed to subside the titration may be carried out to within I per cent. of the correct result.

If it is desirable to determine the amount of carbonate present in an imperfectly burned lime it may be carried on as follows:

After grinding the sample to pass 200 mesh weigh out $650 \mathrm{mg}$. and make the titration in the usual manner; call this result I-available calcium oxid.

Now ignite some of the finely ground sample in a muffle or over a blast and make another determination, using $650 \mathrm{mg}$., calling this result No. 2.

Subtract I from 2 and divide by I. 78 .

Method of Procedure.--The sample must be ground to pass through a 200-mesh screen. Into a $300 \mathrm{cc}$. Erlenmeyer flask place $50 \mathrm{cc}$. of distilled water, then add the $650 \mathrm{mg}$. of the finely ground sample, stopper the flask and shake vigorously for Io seconds, add two drops of solution of phenolphthalein and then run in the standard solution of oxalic acid until the pink color is discharged, then place in the stopper and shake again.

When the color returns, if it is lime, it will be a bright vivid pink, and the addition of perhaps onehalf cc. will be necessary to discharge this color, but if the flask is again shaken and the color returns slowly and is a faint, weak pink this is the end point for the lime.

At all time during the running in of the oxalic acid solution the flask should be shaken as violently as possible, care being taken not to allow it to splash out, so that calcium oxid will pass into solution. In nearly every instance of titrating a high-grade lime the pink color remained vivid nearly to the finish, which shows that the $\mathrm{CaO}$ is rapidly soluble. If a completed titration is allowed to stand for from is minutes to half an hour the pink color will return and show as brightly as in the beginning.

The reading of the burette is in per cent. of calcium oxid. The solutions necessary are:
Oxalic acid, 14.6068 grams of pure crystals dissolved in enough water to make a liter.

Phenolphthalein 0.5 gram dissolved in a mixture of $50 \mathrm{cc}$. alcohol and $50 \mathrm{cc}$. water.

STANFORD UNIV.,

CALIFORNIA.

[CONTRIbution No. 10 from the Research LABoratory of ApPlied Chemistry of the Massachusetts Institute of Technology.]

\section{DIFFERENTIAL CONDENSATION IN DISTILLA- TION AND RECTIFICATION OF BINARY LIQUID MIXTURES.}

By ALCAN HIRSCH.

The object of this paper is to show the important part which condensation plays in distillation and rectification of binary liquid mixtures, and how the efficiency of operation of commercial plants may be increased by proper partial condensation, especially in the case of alcohol-water. The design of total condensers is well understood, and standard textbooks such as Verdampfen Kondensiren und Kühlen, by $\mathrm{E}$. Hausbrand, contain sufficient data on cooling surfaces, radiation, heat transfers, etc., for their correct design and construction. But these same methods of design are usually employed in the case of partial condensers-in fact in commercial practice the same piece of apparatus is often used interchangeably as a partial or total condenser simply by regulating the low of cooling water. It will be shown that in the case of the design of partial condensers several additional factors enter which have not heretofore been taken into account, and that in the great majority of cases the yield obtained from commercial apparatus, both partial condensers and rectifying columns, may be materially increased by proper condensation without increasing the coal consumption under the boilers.

If a mixture of two miscible liquids of difierent boiling points be boiled, the composition of the boiling liquid being kept constant, the vapor evolved will be richer in the more volatile constituent than the liquid, unless the latter be of the constant boiling composition, in which case the vapor is of the same composition as the liquid. The curves showing the composition of the liquid and the composition of the vapor in equilibrium with this liquid have been determined for many difierent mixtures, but for water-ethyl alcohol mixtures with which the experimental part of this paper is concerned, there are three (3) principal curves, as shown in Fig. I; the Grönig, the Rachewsky, and the Sorel. The Grönig is the original data, but Sore ${ }^{1}$ claims that the composition of the vapor in the upper part of Grönig's curve is greater than the true value, due to partial condensation of the vapor in the upper part of the distilling flask, and Sorel has accordingly applied

${ }^{1}$ Compt. rend., 116, 693 . 